\title{
Comparison of Identification of Toxoplasma gondii by Commercial Realtime PCR and Inhouse Realtime PCR Methods
}

\author{
Selma Usluca ${ }^{1}$, Bekir Çelebi ${ }^{2}$ \\ ${ }^{1}$ General Directorate of Public Health, Microbiology Reference Laboratories and Biological Products Department, Ankara, Turkey \\ ${ }^{2}$ General Directorate of Public Health Department of Zoonotic and Vectorial Diseases, Ankara, Turkey
}

Received: 27 April 2019, Accepted: 31 May 2019, Published online: 28 August 2019

(C) Ordu University Institute of Health Sciences, Turkey, 2019

\begin{abstract}
Objective: This study aimed to compare the diagnosis of toxoplasmosis with a commercial kit and inhouse realtime PCR methods to determine molecular methods with high diagnostic accuracy for use in addition to serologic tests for routine diagnosis.

Methods: The study included a total of 116 samples of blood, CSF or amniotic fluid with 19 identified positive and 97 negatives for $T$. gondii sent to our laboratory. Due to the low number of positive samples, DNA samples from an external quality control program that our laboratory participates in were included in the study. First to all samples, realtime PCR method were applied with commercial kit used primers for $T$. gondii rep529 gene, and then inhouse realtime PCR were applied with TG-F and TG-R primers and Taqman probe, targeting the insertion sequence region of $T$. gondii $\mathrm{B} 1$ gene.

Results: The results for the total of 116 samples studied with both methods was that 17 were identified as positive with commercial realtime PCR and 19 were determined as positive with inhouse realtime PCR. Accordingly, two cases with the commercial realtime PCR method were determined as false negative. The limit of detection for both methods used in our study was determined as $10-3$ dilution ( 0.028 copy/reaction). There was a high level of compatibility determined between the inhouse and realtime PCR methods (kappa value: 0.934).

Conclusion: In conclusion, though there was perfect compatibility observed between the results with the two methods, disadvantages of the commercial realtime PCR method included isolates where the target gene was not found, deletion or mutation of all or part of this gene or different numbers of repeats causing false negative results and high cost. Considering this, our laboratory decided to use the inhouse realtime PCR using primers for the B1 gene to research $T$. gondii with molecular methods. A significant limitation of the study is the low number of positive samples. For DNA samples belonging to the External Quality Control Program, the commercial kit was $66.66 \%$ successful, while the inhouse realtime PCR method was $100 \%$ successful.
\end{abstract}

Key words: Inhouse realtime $P C R$, realtime $P C R, T$. gondii

Suggested Citation: Usluca S, Celebi B. Comparison of Identification of Toxoplasma gondii with Commercial Realtime PCR and Inhouse Realtime PCR Methods. Middle Black Sea Journal of Health Science, 2019; 5(1): 79-84

Address for correspondence/reprints:

Selma Usluca

Telephone number: +90 (505) 2537123

E-mail: selmausluca@gmail.com

DOI: $10.19127 / \mathrm{mbsjohs} .558436$

\section{Introduction}

Toxoplasma gondii (T. gondii) is an obligate intracellular apicomplexan parasite responsible for opportunistic infections in patients with immune suppression and infects all warm-blooded vertebrates including mammals and birds (Sails, 2004; Su et al., 2010; Robert-Gangneux and Belaza, 2016; Rajendran et al., 2018). Cats are definite hosts (Rajendran et al., 2018). Infection may occur by eating raw or poorly cooked meat containing tissue 
cysts, drinking water contaminated by oocysts from feces of infected cats or eating fruit-vegetables washed in this water. Just as infection may be observed through blood or organ transplantation, the tachyzoite form may be transferred in congenital infection from mother to child (Hill and Dubey, 2002; Sails, 2004; Su et al., 2010; Rajendran et al., 2018; Rostami et al., 2018). Infection is generally asymptomatic and self-limiting, especially in hosts with stable immune system (Hill and Dubey, 2002; Su et al., 2010; Rajendran et al., 2018). However, lymphadenopathy, fever, fatigues, muscle pain, throat pain and headache or ocular toxoplasmosis may be observed in some patients (Hill and Dubey, 2002; Su et al., 2010). Due to the presence of tissue cysts, it may remain as lifelong latent infection (Switaj et al., 2005). When congenital infection is obtained in the first trimester, it causes more severe clinical findings compared to transmission in the second and third trimester (Hill and Dubey, 2002). It may cause miscarriage especially in early pregnancy, stillbirth and congenital anomalies (Hill and Dubey, 2002; Su et al., 2010; Rajendran et al., 2018). For patients with suppressed immune systems such as those infected during pregnancy, fetuses and neonates with intrauterine infection, HIV patients, patients with organ transplantation and retinochoroiditis patients, the diagnosis is critical (Rostami et al., 2018). Diagnosis may be made with microscopic investigation of smears from tissue obtained by biopsy or autopsy stained with Giemsa (Hill and Dubey, 2002). Parasite may isolated with inoculation of laboratory animals and tissue cultures with these clinical samples, and additionally by secretions and body fluids obtained from patients (Hill and Dubey, 2002; Su et al., 2010). However, these methods are not practical, require intense effort and a few days to obtain results (Calderaro et al., 2006; Fallahi et al., 2015). Routine diagnosis of disease is based on serologic methods especially (Su et al., 2010; Rostami et al., 2018). Diagnostic methods like Sabin Feldman Dye testi (SFDT), IFAT, latex agglutination test (LAT), IHA, ELISA, modified agglutination test (MAT), western blot (WB), and IgG avidity tests are used (Hill and Dubey, 2002; Rostami et al., 2018). In recent years, immunological methods like CLIA, ELFA, immunochromatography tests and ISAGA have been developed (Rostami et al., 2018). Antibody titrations remaining high after clinical amelioration of infected people make it difficult to interpret the results of these serologic tests (Hill and Dubey, 2002). The most important limitation of these methods is the inability to fully estimate the infection duration. Serologic diagnosis is difficult for patients with congenital infection or immune failure (Wastling et al., 1993; Switaj et al., 2005). In these patients with insufficient or disrupted immune response, effective, rapid, and accurate diagnosis is important to be able to begin treatment. Molecular techniques are very beneficial for these patients as evaluation of results is not linked to the immune status of the host (Wastling et al., 1993; Switaj et al., 2005; Calderaro et al., 2006; Fallahi et al., 2015). Especially, realtime PCR methods are commonly used due to high sensitivity and specificity (Fallahi et al., 2015; Rostami et al., 2018).

Just as around the world, toxoplasmosis is a significant health problem in Turkey and the use of serology and molecular methods together is recommended for cases to strengthen diagnosis, especially for cases experiencing diagnosis problems. This study aimed to compare diagnosis of toxoplasmosis with a commercial and inhouse realtime PCR methods to determine molecular methods with high diagnostic accuracy for use in addition to serologic tests for routine diagnosis.

\section{Methods}

The study, included a total of 116 samples of blood, CSF or amniotic fluid with 19 identified positive and 97 negative for $T$. gondii sent to our laboratory. Due to the low number of positive samples, DNA samples from an External Quality Control Program that our laboratory participates in were included in the study. Samples were applied DNA exraction with a commercial DNA extraction kit (QIAmp DNA mini kit, Qiagen, Germany) used in accordance with the manufacturer's. DNA isolation was performed with commercial kit from T. gondii strain which was carried out with mouse passage in our laboratory. Limit of detection study was performed with serial dilutions of this DNA sample prepared with $1 / 10$ dilutions. The obtained DNA samples used two different realtime PCR methods for verification in our laboratory for identification of $T$. gondii. Realtime PCR method was applied to all samples first by using commercial T. gondii rep529 gene primers (Genesig, Primer Design, UK), according to manufacturer's recommendations. Then as recommended by Lin et al. TG-F (5'-CTTCGTCCAAGCCTCCGA-3') and TG-R (5'-GACGCTTTCCTCGTGGTGAT-3') primers and Taqman probe (6-FAMTCTGTGCAACTTTGGTGTATTCGCAG-BHQ-

1) were used targeting the insertion sequence region of the $T$. gondii B1 gene for inhouse realtime PCR. 
Optimization studies were performed to determine the synthesized primers and best study concentrations for the probe. According to the results of this study for $20 \mu 1$ reaction mix, reaction volume was set with LightCycler probe mastermix (Roche, Mannheim, Germany) $10 \mu 1,1 \mu 1$ of each primer $(10 \mathrm{pmol})$, probe $(4 \mathrm{pmol}) 0.4 \mu \mathrm{l}$, molecular grade water $5.6 \mu 1$ and DNA $2 \mu 1$. The amplification cycles of PCR was $95^{\circ} \mathrm{C} 5$ min initial denaturation, 40 cycles of two stage $95{ }^{\circ} \mathrm{C} 15 \mathrm{~s}$ denaturation, 60 ${ }^{\circ} \mathrm{C} 30 \mathrm{~s}$ annealing- extension studied in a LightCycler realtime device (Roche, Mannheim, Germany) (Lin et al., 2000).

\section{Results}

DNA extraction was performed with a commercial kit using $200 \mu 1(2,800$ tachyzoite $) T$. gondii strain $(14,000$ tachyzoite/ml) obtained by mouse passage in our laboratory. At the end of extraction, DNA was obtained within $200 \mu$ l elution buffer (2,800 genomic DNA). In PCR reaction used $2 \mu 1$ DNA. Limit of detection studies were performed with serial dilutions prepared with $1 / 10$ dilution of the DNA sample. The limit of detection for both methods used in our study was determined as $10^{-3}$ dilution $(0,028$ copy/reaction $)$. The comparison of CT values belonging to limit of detection of samples with both methods is given in Table 1. The inhouse realtime PCR limit of detection studies determined 3.51-3.44 difference between CTs of dilutions, while the commercial realtime PCR limit of detection study found 4.729.79 difference between CTs of dilutions. The results for the total of 116 samples studied with both methods was that 17 were identified as positive with commercial realtime PCR and 19 were determined as positive with inhouse realtime PCR. Accordingly, two cases with the commercial realtime PCR method were determined as false negatives (Table 2). There was a high level of compatibility determined between the inhouse and commercial realtime PCR methods (kappa value: 0.934). The results of studying DNA samples belonging to the external quality control program identified five positives and one negative correctly as determined by the program organizer with the inhouse realtime PCR, while the commercial realtime PCR method determined two positive samples as being negative (Table 3 ).
Table 1: Comparison of CT values of Inhouse realtime PCR and commercial kit

\begin{tabular}{lll}
$\mathbf{1 0}^{-1}$ & $\mathbf{1 0}^{-2}$ & $\mathbf{1 0}^{-3}$ \\
dilution & dilution & dilution \\
$(\mathbf{2}, 8$ copy $)$ & $(28$ copy $)$ & $\begin{array}{l}(0,028 \\
\text { copy })^{*}\end{array}$ \\
\hline
\end{tabular}

\begin{tabular}{lccc}
\hline $\begin{array}{l}\text { Inhouse } \\
\text { Realtime PCR } \\
\text { CT values }\end{array}$ & 25.05 & 28.56 & 32 \\
$\begin{array}{l}\text { Commercial } \\
\text { Realtime PCR } \\
\text { CT values }\end{array}$ & 18.73 & 23.45 & 33.24 \\
\hline
\end{tabular}

* Limit of detection

Table 2: Comparison of Inhouse realtime PCR method with commercial kit.

\begin{tabular}{llccc}
\hline \multirow{2}{*}{$\begin{array}{l}\text { Commercial } \\
\text { Realtime }\end{array}$} & \multicolumn{4}{c}{$\begin{array}{c}\text { Inhouse Realtime PCR } \\
\text { Positive }\end{array}$} \\
\cline { 2 - 5 } PCR & Positive & 17 & 0 & 17 \\
& Negative & 2 & 97 & 99 \\
& Total & 19 & 97 & 116 \\
\hline
\end{tabular}

Table 3: Results of External Quality Control Program samples with commercial and inhouse realtime PCR method.

\begin{tabular}{cccc}
\hline & $\begin{array}{c}\text { Intended } \\
\text { Results }\end{array}$ & $\begin{array}{c}\text { Inhouse } \\
\text { Realtime } \\
\text { PCR Results }\end{array}$ & $\begin{array}{c}\text { Commercial } \\
\text { Realtime } \\
\text { PCR Results }\end{array}$ \\
\hline Sample 1 & Positive & Positive & Positive \\
Sample 2 & Positive & Positive & Positive \\
Sample 3 & Positive & Positive & Negative* \\
Sample 4 & Negative & Negative & Negative \\
Sample 5 & Positive & Positive & Negative* \\
Sample 6 & Positive & Positive & Positive \\
\hline
\end{tabular}

* False negative samples

\section{Discussion}

Among molecular methods for diagnosis of toxoplasmosis, the most commonly used are conventional PCR, nested PCR and realtime PCR methods (Su et al., 2010). Conventional PCR method is beneficial, but has low sensitivity and specificity and is a very laborious and timeconsuming method (Sails, 2004). Nested PCR increases specificity of DNA amplification and is used to identify very small amounts of the pathogen. However, this method involves higher contamination risk and as a result has low specificity (Robert-Gangneux and Belaza, 2016; Rostami et al., 2018). Realtime PCR is a method making it possible to diagnose the pathogen and determine parasite load in clinical samples and has high diagnostic accuracy. It is the most sensitive molecular method to identify target DNA especially at low concentrations (Sails, 2004, Calderaro et al., 2006; Su et al., 2010; Ivović V et al., 2012; Rostami et al., 2018). Quantitative realtime PCR determines decreasing parasite loads in clinical samples like 
blood, BAL and CSF offering the opportunity to monitor treatment efficacy (Sails, 2004; RobertGangneux and Belaza, 2016; Rostami et al., 2018). Due to the closed system, there is low risk of amplicons contaminating the environment and low possibility of false positive results with probes able to measure amplification products in each cycle leading to the superiority of realtime PCR (Sails, 2004; Rostami et al., 2018). This method also can identify the DNA of more than one pathogen in the same tube. Due to this, the number of laboratories using realtime PCR methods is rapidly increasing.

In this study, we aimed to compare two PCR methods to select a realtime PCR with high diagnostic accuracy for use in our laboratory. When both methods are compared in our study, four samples had incompatible results. The reasons for these incompatible results may be inhibitors not removed during DNA extraction from the matrix of the examined sample, target regions used and master mix composition used in the method or inability to optimize the amplification thermal cycle well.

When sample matrix is investigated, two of the samples with incompatible results were blood, one was amniotic fluid and one was CSF. Due to the low number of samples, it is notable that two samples with incompatible results were whole blood samples. Heme is a significant inhibitor for PCR (Cardona et al., 2011). Inhibitors from the samples in the DNA extraction stage may prevent good shaping of the reaction. There may not be sufficient reagents in the mastermix used to prevent effects from inhibitors. Incompatibility may be observed among results obtained in this situation. Procedures used when studying blood samples (isolation of leukocyte cells from 5 or $10 \mathrm{~mL}$ whole blood or direct DNA extraction from full blood) may change the PCR results. Parasite load identified in the buffy coat obtained from $1200 \mu \mathrm{l}$ blood is reported to be higher than that obtained from $200 \mu \mathrm{l}$ blood. As $T$. gondii proliferates in leukocyte cells and whole blood contains PCR inhibitors, it should be remembered that sensitivity may reduce (RobertGangneux and Belaza, 2016).

Another important factor affecting sensitivity and specificity is the selection of DNA target and primers (Calderaro et al., 2006; Mousavi et al., 2016). Identification of the single copy gene on the surface of P30 protein was the first target gene used for identification of $T$. gondii DNA with PCR (Robert-Gangneux and Belaza, 2016). However, the sensitivity of single copy genes like P30 is low and as a result it is chosen less often today ( $\mathrm{Su}$ et al,
2010; Ivović et al., 2012). Later, 30 to 300 repeated sequence targets are recommended in the parasite genome (Robert-Gangneux and Belaza, 2016). One of the target genes still most commonly used for molecular identification of $T$. gondii is the B1 gene with 35 repeats in the genome. This gene is conserved at high rates in all $T$. gondii strains (Switaj et al., 2005; Calderaro et al., 2006; Su et al., 2010; Ivović et al., 2012; Rostami et al., 2018). Following this, a few multiple copy target genes including 18S rRNA and ITS-1 genes, rep529 repeated fragment or AF146527 element (300 copy target gene) are used (Su et al., 2010; Ivović et al., 2012; Rostami et al. 2018). Studies have reported PCR of ITS-1 and 18S rDNA sequences have similar sensitivity for the B1 gene (Su et al., 2010; Switaj et al., 2005; Liu et al., 2015). PCR targeting the multiple copy gene of rep529 gene is reported to be 10-100 times more sensitive than the $\mathrm{B} 1$ gene (Switaj et al., 2005; Su et al., 2010; Ivović et al., 2012; Liu et al., 2015; Rostami et al., 2018). Due to the high sensitivity and specificity of realtime quantitative PCR, currently these two target genes are more commonly used and comparisons of these are found in many studies. When these studies are assessed, in addition to studies reporting the rep529 gene is more successful (Hierl et al., 2004; Belfort et al., 2008; Sterkers et al., 2010; Robert-Gangneux et al., 2017), there are studies reporting the B1 gene is more successful (Wahab et al., 2010; Cardona et al., 2011; Mousavi et al., 2016; Kalantari et al., 2017). Diagnostic performance for identification of T. gondii with PCR may be affected by many factors like repeat number of the target and target series polymorphism or absence (Teixeira et al., 2013). The true repeat numbers of the target genes are still a topic of debate and may be lower than expected or may display differences between parasite strains (Robert-Gangneux and Belaza, 2016). Some recent studies have reported the copy number for the rep529 gene in the Toxoplasma genome is lower than the 5 to 12 times found in previous studies (Ivović et al., 2012). Again, some studies comparing the B1 gene and AF146527 gene reported false negative results for some samples with the AF146527 gene. The reason for this is considered to be the rep529 gene not being found in all isolates analyzed, deletion or mutation of all or fragments of it or repeat numbers being different in parasite strains (Wahab et al., 2010; Ivović et al., 2012). Before a diagnostic laboratory brings a protocol using AF146527 repeated fragments, it is necessary to reveal the specificity very well (Wahab et al., 2010). In our study, four samples with false 
negatives determined are considered to be due to absence or polymorphism of the rep529 gene.

One of the factors affecting sensitivity and specificity is the amplification conditions (Calderaro et al., 2006). In amplification conditions, the annealing temperature of primers is important. Optimization studies were performed to determine the best annealing temperature for the inhouse PCR method. Annealing temperatures may display differences from device to device. Although commercial kits are based on recommendations in the manufacturer's instruction, sometimes may not have optimum efficiency. The incompatibility of results obtained in our study may due to this reason.

When calculating the amplification efficiency of realtime PCR, the CT differences between dilutions are important. A $100 \%$ efficient reaction will provide 10 -fold increase $(\log 10=3.3219)$ in PCR amplicon in every 3.32 cycles in the amplification exponential phase. The mean $\mathrm{CT}$ difference between DNA samples diluted 10-fold should be 3.32. CT difference larger than 3.32 (i.e. 3.9) shows efficiency lower than $100 \%$, while CT difference lower than 3.32 (i.e. 2.5) shows problems with sample quality or pipetting (ThermoFisher manual). For our inhouse realtime PCR, limit of detection studies determined 3.51-3.44 CT difference between dilutions, while for the commercial realtime PCR limit of detection studies found 4.729.79 CT difference between dilutions. According to this data, the CT difference being above 3.9 may be assessed as the commercial kit having low efficiency. The result of studying DNA samples with known content from the External Quality Control Program identified five positives and one negative with inhouse realtime PCR, while two positive samples were determined as negative with the commercial realtime PCR method. The efficiency of the commercial kit was not found to be high when assessing positive samples.

\section{Conclusion}

In conclusion, though there was perfect compatibility observed between the results with the two methods in terms of kappa value, disadvantages of the commercial realtime PCR method included isolates where the target gene was not found, deletion or mutation of all or part of this gene or different numbers of repeats causing false negative results and high cost. Considering this, our laboratory decided to use the inhouse realtime PCR using primers for the $\mathrm{B} 1$ gene to research $T$. gondii with molecular methods. A significant limitation of the study is the low number of positive samples. For DNA samples belonging to the External Quality
Control Program, the commercial kit was $66.66 \%$ successful, while the inhouse realtime PCR method was $100 \%$ successful. As a result, it is considered that more comprehensive studies increasing the the number of positive samples will increase the reliability of the results.

Ethics Committee Approval: Patients' consent was obtained in the use of microbiological data.

Peer-review: Externally peer-reviewed.

Author Contributions: Concept - SU, BC Design

SU, BC; Supervision SU, BC; Materials - ........,; Data Collection and/or Processing - SU, BC; Analysis and/or Interpretation - SU; Literature Review - SU, BC; Writing - SU, BC; Critical Review - SU, BC

Conflict of Interest: No conflict of interest was declared by the authors.

Financial Disclosure: The authors declared that this study hasn't received no financial support.

\section{References}

Belfort R, Isenberg J, Fernandes BF, DiCesare S, Belfort $\mathrm{Jr} \mathrm{R}$, Burnier $\mathrm{Jr} \mathrm{MN}$, Evaluating Different Methods of Toxoplasma Gondii Detection in Peripheral Blood, Invest Ophth Vis Sci, 2008;49(13):1-9.

Calderaro A, Piccolo G, Gorrini C, Peruzzi S, Zerbini L, Bommezzadri S, Dettori G, Chezzi C, Comparison Between two Real-time PCR Assays and a Nested-PCR for the Detection of Toxoplasma gondii, Acta Biomed, 2006;77:7580.

Cardona N, Basto N, Parra B, Zea AF, Pardo CA, Bonelo A, G'omez-Marin JE, Detection of Toxoplasma DNA in the Peripheral Blood of HIVPositive Patients with Neuro-opportunistic Infections by a Real-Time PCR Assay, J Neuroparasitology, 2011;2:1-6.

Fallahi S, Mazar ZA, Ghasemian M, Haghighi A, Challenging Loop-Mediated Isothermal Amplification (LAMP) Technique for Molecular Detection of Toxoplasma gondii, Asian Pac J Trop Med, 2015;366-372. 
Hierl T, Reischl U, Lang P, Hebart H, Stark M, Kyme P, Autenrieth IB, Preliminary Evaluation of one Conventional Nested and two Real-time PCR Assays for the Detection of Toxoplasma gondii in Immunocompromised Patients, J Med Microbiol, 2004;53:629-632.

Hill D, Dubey JP, Toxoplasma gondii: Tansmission, Diagnosis and Prevention, Clin Microbiol Infect, 2002;8:634-640.

Ivović V, Vujanić M, Živković T, Klun I, Djurković-Djaković O, Molecular Detection and Genotyping of Toxoplasma gondii from Clinical Samples in: Toxoplasmosis - Recent Advances, Ed: Djurković-Djaković O, InTech Open Access Publisher, 2012;103-119.

Kalantari N, Darabi ZA, Siadati S, Nikbakhsh N, Ghasemi M, Ghaffari T, Ghaffari S, Bayani M, Detection of Toxoplasma gondii DNA in Malignant Breast Tissues in Breast Cancer Patients, Int J Mol Cell Med, 2017;6(3):190-196.

Lin MH, Chen TC, Kuo TT, Tseng CC, Tseng CP, Real-Time PCR for Quantitative Detection of Toxoplasma gondii, J Clin Microbiol, 2000;38(11): 4121-4125.

Liu Q, Wang ZD, Huang SY, Zhu XQ, Diagnosis of Toxoplasmosis and Typing of Toxoplasma gondii, Parasites and Vectors, 2015;8:292-305.

Mousavi M, Saravani R, Modrek MJ, Shahrakipour M, Sekandarpour S, Detection of Toxoplasma gondii in Diabetic Patients Using the Nested PCR Assay via RE and B1 Genes, Jundishapur J Microbiol, 2016;9(2):1-6.

Rajendran C, Keerthana CM, Anilakumar KR, Satbige AS, Gopal S, Development of B1 Nested PCR for Assessing the Prevalence of Zoonotic Protozoan Disease Agent Toxoplasma Gondii among Food Animals from Karnataka State, Southern India, J Microbiol Lab Sci, 2018;1(1): $1-8$.

Robert-Gangneux F, Belaza S, Molecular Diagnosis of Toxoplasmosis in Immunocompromised Patients, Wolters Kluwer Health, 2016;29(4): 330-339.

Robert-Gangneux F, Brenier-Pinchart MP, Yera H, Belaz S, Varlet-Marie E, Bastien P, Molecular Biology Study Group of the French National Reference Center for Toxoplasmosis, Evaluation of Toxoplasma ELITe MGB, Real-Time PCR Assay for Diagnosis of Toxoplasmosis, J Clin Microbiol, 2017;55(5):1369-1376.
Rostami A, Karanis P, Fallahi S, Advances in Serological, Imaging Techniques and Molecular Diagnosis of Toxoplasma gondii Infection, Infection, 2018;1-13.

Sails AD, Applications in Clinical Microbiology in: Real-time PCR: An Essential Guide, Eds: Edwards, Logan, Saunders, Horizon Scientific Press, Wymondham, UK, 2004:247-326.

Sterkers Y, Varlet-Marie E, Cassaing S, BrenierPinchart MP, Brun S, Dalle F, Delhaes L, Filisetti D, Pelloux H, Yera H, Bastien P, Multicentric Comparative Analytical Performance Study for Molecular Detection of Low Amounts of Toxoplasma gondii from Simulated Specimens, J Clin Microbiol, 2010;48(9):3216-3222.

Su C, Shwab EK, Zhou P, Zhu XQ, Dubey JP, Moving towards an Integrated Approach to Molecular Detection and Identification of Toxoplasma gondii, Parasitology, 2010;137, 111.

Switaj K, Master A, Skrzypczak M, Zaborowski P, Recent Trends in Molecular Diagnostics for Toxoplasma gondii Infections, Clin Microbiol Infect, 2005;11: 170-176.

https://assets.thermofisher.com/TFS-

Assets/LSG/manuals/cms_042380.pdf

Teixeira LE, Kanunfre KA, Shimokawa PT, Targa LS, Rodrigues JC, Domingues W, Yamamoto L, Okay TS, The Performance of four Molecular Methods for the Laboratory Diagnosis of Congenital Toxoplasmosis in Amniotic Fluid Samples, Rev Soc Bras Med Trop, 2013;46(5):584-588.

Wahab T, Edvinsson B, Palm D, Lindh J, Comparison of the AF146527 and B1 Repeated Elements, Two Real-Time PCR Targets Used for Detection of Toxoplasma gondii, J Clin Microbiol, 2010;48(2):591-592.

Wastling JM, Nicoll S, Buxton D, Comparison of two Gene Amplification Methods for the Detection of Toxoplasma gondii in Experimentally Infected Sheep, Med Microbiol, 1993; 38:360-365. 